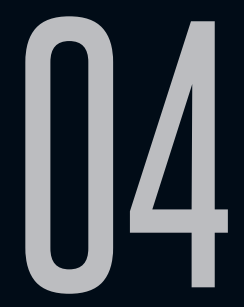

\title{
OS QUADRINHOS DE FICÇÃO CIENTÍFICA BRASILEIROS DOS ÚLTIMOS ANOS
}

Lielson Zeni (UFRJ)

Recebido em 30 out 2019. Lielson Zeni é Doutorando na UFRJ, Mestre em Aprovado em 26 fev 2020. Estudos Literários (UFPR), Graduado em Comunicação Social (UFPR) e Letras (UFPR).

Resumo: Como é o cenário atual da ficção científica brasileira, escrita em português, nas histórias em quadrinhos? Em busca dessa resposta foi pesquisado quais foram os lançamentos dentro dessa área da ficção especulativa nos anos de 2017, 2018 e parte de 2019. Para isso, foram listadas as obras lançadas no Brasil no período, levando em conta as particularidades do processo de publicação de histórias em quadrinhos em nosso país.

Palavras-chave: História em Quadrinhos; Ficção Científica; Fanzine; Publicação Independente; Ficção Científica em Quadrinhos.

Abstract: What is the current scenario of Brazilian science fiction, written in Portuguese, in comics? Looking for this answer it was researched what was the speculative fiction' releases in years 2017, 2018 and part of 2019. So, it was listed brazilian works in this time, and it was think about brazilian comics publication details.

Keywords: Comics; Science Fiction; Fanzine; Independent Publications; Sci-Fi Comics. 


\section{APRESENTAÇÃO}

A publicação de histórias em quadrinhos no Brasil atualmente tem uma grande variedade de estilos, de influências e de meios de editoração. Verdade seja dita, gêneros como aventura, humor, terror, ficção científica, drama cotidiano, policial, alta fantasia, dentre muitos outros, são publicados em nosso país desde as primeiras edições que traziam traduções de materiais, em grande parte, oriundos dos Estados Unidos.

Os suplementos semanais dedicados ao público infantil, como Gibi e Tico-Tico, foram algumas das primeiras publicações brasileiras dedicadas às histórias em quadrinhos no início do século XX. Na década de 1960 houve uma enorme quantidade de revistas de terror primeiramente com traduções e em seguida com material produzido nacionalmente. Em meio às histórias de horror apresentam-se exemplares de ficção científica que já se misturam com outros gêneros, não apenas nas publicações bastante ecléticas, mas nos próprios roteiros abertos o bastante para receber elementos de diversos gêneros.

Nos anos de 1980, o humor paulistano vai tomar as bancas do país, com histórias pensadas para fazer rir e repetidas vezes vão lançar mão de elementos insólitos; as principais publicações desse período vão ser as revistas Chiclete com Banana, de Angeli, Piratas do Tietê, de Laerte e Geraldão, de Glauco, todas da Circo Editorial, ligadas ao editor Toninho Mendes.

Em paralelo a essa publicação de autoria nacional, o Brasil vai ser um grande consumidor de material traduzido, como Disney, que foi o segundo título de história em quadrinhos da editora Abril após 
o fracasso com o quadrinho de ação Raio Vermelho. "Dois meses depois, em 12 de julho [de 1950], Civita lançou o primeiro número de $O$ Pato Donald, que o editor passou a considerar como sua primeira publicação" (JUNIOR, 2004, p.166). A Abril seguiria com a licença da Disney até 2018, além de publicar os super-heróis da Marvel e da DC, que passaram por diversas editoras ao longo das últimas décadas e estão estabilizados a praticamente 20 anos na editora Panini.

Como exemplo mais ligado ao tema deste texto, a ficção científica, o personagem de aventuras espaciais e futuristas criado e desenhado por Alex Raymond, "[...] Flash Gordon, [foi] visto por aqui sob a forma de páginas dominicais de histórias em quadrinho sindicalizados (pelo King Features Sindycate) e publicadas no Suplemento Juvenil, a partir de março de 1934" (CAUSO, 2003, p.188).

Embora esteesforço de coleta de dadosse dedique exclusivamente a obras de autoria nacional, é inegável o impacto e a influência que as obras traduzidas têm no público leitor e nos produtores de histórias em quadrinhos do Brasil. Caso se empreenda um esforço de análise de obra a obra, será perceptível a dura influência da indústria cultural de grandes centros em países periféricos: muitas obras inspiradas nos super-heróis estadunidenses, seja nos maneirismos reconhecíveis do traço super-heroico, como musculatura superdesenvolvida e aparente, seja no processo de produção das páginas que segue o desenho à lápis, arte-final à nanquim e cor digital, seja nos temas do ser escolhido como protetor ou vingador de uma comunidade, que enfrenta com violência e os punhos suas consequências e não suas causas. Ou, em menor escala, os quadrinhos de caubóis em preto e branco de arte naturalista que busca sua validação na semelhança às 
narrativas do personagem Tex, da editora italiana Bonelli; ou mesmo os bárbaros de cabelos longos e seminus que derrotam monstros e adversários com o ferro frio de sua espada, muito parecidos com a personagem Conan, criada por Robert E. Howard, hoje licenciado para a Marvel e cujas andanças de publicação nos Estados Unidos e alternância de direitos patrimoniais mereceriam a atenção de um artigo dedicado a isso.

Entretanto, não só de influência direta de outros quadrinhos e de pastiches forma-se o fantástico brasileiro das histórias em quadrinhos, com muitas narrativas inspiradas na literatura, tanto nacional quanto estrangeira, em filmes e séries, e tantas outras fontes de inspiração possíveis para a criação da ficção científica.

Nem todas as obras catalogadas neste estudo se preocupam em ocupar um cenário que beba mais do imaginário brasileiro, por mais disputada que seja a noção do que seria esse imaginário. Uma das dificuldades de catalogação, além da ausência de um banco de dados oficial e alto grau de confiabilidade, é, justamente, como a ficção científica surge tematicamente nos livros, fanzines e revistas, mesclada a outros gêneros ou categorias, tanto do insólito quanto do realismo ou mesmo como uma variação por conta da faixa etária. Por exemplo, essa pesquisa não foi capaz de avaliar as revistas infantis do estúdio Mauricio de Sousa, seja na turma clássica ou em sua versão Turma Jovem. Personagens como Astronauta e Franjinha, o menino cientista do bairro do Limoeiro, levam as histórias da turminha para os vieses da ficção científica.

Inclusive, uma das formas de ficção especulativa não encontrada na literatura brasileira por Roberto de Sousa Causo, 
no período entre 1875 e 1950, o romance pré-histórico, tem um representante no núcleo de histórias do personagem de Mauricio de Sousa, Piteco. "A fascinação dos franceses pelas descobertas paleontológicas realizadas em seu país e no restante da Europa - a partir da descoberta das pinturas rupestres de Altamira em 1875 - nunca se transferiu para o Brasil, apesar da influência francesa sobre nosso país" (CAUSO, 2003, p.204). Embora as histórias das revistas infantis tratem mais de humor do que de outras abordagens narrativas, as duas Graphic MSP - projeto da Mauricio de Sousa Produções - dedicadas ao personagem pré-histórico vão nessa direção - a saber: Piteco: Ingá, de Shiko (Panini, 2013) e Piteco: Fogo, de Eduardo Ferigato (Panini, 2019). Esse selo da MSP propõe que personagens de Mauricio de Sousa sejam reinterpretados por outros autores em histórias mais longas, publicadas em álbuns e, com exceção da série do Astronauta, de Danilo Beyruth, não sequenciais. Já a Turma da Mônica Jovem tem em uma de suas primeiras aventuras, uma viagem pelo espaço e o confronto com seres alienígenas, com roteiro de Flavio Teixeira de Jesus e arte do estúdio da Mauricio de Sousa Produções, ou seja, com envolvimento de diversos profissionais em um processo em que cada um faz uma quantidade de páginas - nessa época a política da empresa era não creditar os desenhistas.

Vale citar também as edições especiais com paródias de séries com os personagens da turminha no lugar dos atores, como Coelhada nas Estrelas (Panini, 2017), Coelhada para o Futuro (Panini, 2013) e Trônica (Panini, 2012), que parodiam, respectivamente as franquias de filmes, Guerra nas Estrelas, De volta Para o Futuro e Tron, e todas elas também com roteiro de Flavio Teixeira de Jesus e 
desenho do estúdio da Mauricio de Sousa Produções. São histórias em quadrinhos derivadas de filmes, em que o mesmo elemento da ficção científica da obra-fonte está presente, mesclado com as idiossincrasias dos personagens da Turma da Mônica e ajustados para agradar aos leitores de Mauricio de Sousa.

Por mais promissora que a investigação pudesse ser, diante da clara incapacidade de lidar com essa quantidade de dados, optouse por manter o foco em quadrinhos não direcionados ao público infantil, posição que permitiu, pelo menos, contabilizar os álbuns da linha Graphic MSP.

\section{CRITÉRIOS ADOTADOS PARA A OBTENÇÃO DOS DADOS}

Antes da apresentação dos dados, explicita-se a maneira que eles foram obtidos. O critério foi de buscar por obras de história em quadrinhos originalmente lançadas no Brasil, em português (ou sem palavras) e com autoria brasileira, o que exclui questões como se uma história das Tartarugas Ninjas desenhada pelo brasileiro Mateus Santolouco deveria entrar na contagem.

Dentre essa massa de publicações, um novo recorte foi imposto: somente as histórias em quadrinhos que tratassem do insólito seriam do interesse da pesquisa. Para uma adequação mais precisa aos propósitos desta publicação, as atenções centraramse especificamente na ficção científica, de maneira bastante abrangente, o que criou a necessidade de um novo recorte por causa da enorme quantidade de publicações da Turma da Mônica, e a retirar da contagem as histórias em quadrinhos infantis.

Restringiu-se também a coleta de dados a obras que tenham existência física impressa, independente da quantidade de páginas, 
formato e acabamento gráfico. A razão para isso é que a possibilidade de ficar ainda mais longe da totalidade das informações era muito maior ao se incluir as histórias em quadrinhos lançadas somente na internet, seja em redes sociais como Instagram, Facebook ou Twitter, seja em ambiente próprio como site pessoal, blog ou portal.

O período escolhido foi restrito e compreendeu as publicações lançadas de janeiro de 2017 a setembro de 2019, incluindo todo o período, sem saltos. A justificativa para essa escolha é trazer uma quantidade razoável de dados, que possibilitaria algumas comparações e o seu manejo, mas que não geraria material excessivo, o que inviabilizaria a conferência das informações dado seu alto volume, se considerar os propósitos deste texto, que se trata de uma empreitada de menor fôlego e de um único pesquisador.

Acredita-se também que usar períodos tão próximos temporalmente da redação deste artigo possa mostrar uma espécie de instantâneo interessante deste momento, pois os tempos recentes são comumente deixados para depois, para serem apreciados quando viram os "tempos atrás". O motivo do ano de 2019 ir até setembro acontece por conta da escrita acontecer em outubro, portanto, a coleta foi fechada no período mais próximo possível que ainda permitisse o tempo para redigir este artigo.

A quantidade de dados apresentados a seguir confirma como uma pesquisa mais ampla demandaria muito mais tempo, dedicação e pesquisadores. Acredita-se, que por enquanto, esse instantâneo já é capaz de fomentar algumas discussões e apontar perspectivas dentro do cenário brasileiro, tanto para a ficção científica quanto para as histórias em quadrinhos. 


\section{A IDENTIFICAÇÃO COMO FICÇÃO CIENTÍFICA}

Para a identificação de uma obra como ficção científica, adotou-se dois critérios: o primeiro deles é o de autoidentificação, em que o próprio autor ou a própria autora (ou a editora) aponta que sua obra está nesse contexto, seja na sinopse, na promoção de venda, na capa ou em qualquer outro tipo de marca editorial, ou mesmo em entrevistas em que o autor atribui a sua obra essa marca; o segundo foi quando o catalogador dos dados considerou que a obra se encaixasse como ficção científica. Para o segundo caso, usou-se leitura e análise, resenhas, comentários e entrevistas de autores. Quando foi preciso que o próprio catalogador decidisse se havia ou não o enquadramento da obra, considerou-se que era ficção científica de acordo com o seguinte critério, apresentado por João Adolfo Hansen, no prefácio do livro de Fiç̧ão Científica, Fantasia e Horror no Brasil: 1875 a 1950, de Roberto de Sousa Causo:

A ficção especulativa teria três divisões, sendo uma delas a ficção científica. Digamos brevemente que o subgênero da "ficção científica", como a define, põe em cena metáforas da ciência e da tecnologia, geralmente em uma narrativa de "viagem fantástica" por espaços-tempos incomuns, profundezas da Terra, interior do corpo humano, planetas de outros sistemas, florestas ou desertos primitivos, o passado de civilizações lendárias, Lemúria, Atlântida, Manoa, ou o improvável futuro humano, devastado por guerras nucleares e civilizações cruéis e sanguinárias ou absolutamente pacificados sob a direção ilustradíssima de filósofos e cientistas realizando a coisa assustadora que é a república platônica. (CAUSO, 2003, p.18-19) 
A partir dessas considerações houveram a coleta e a catalogação das informações que geraram a lista disponível no Anexo, após as figuras.

\section{MÉTOdO DE COLETA DE DADOS}

A pesquisa aconteceu em consulta de arquivo pessoal e por meio de pesquisa eletrônica em bancos de dados disponíveis na internet. As publicações das editoras estabelecidas foram diretamente obtidas nos sites oficiais dessas editoras, o que gerou apenas o trabalho de organização e criação das tabelas para a contagem dessas informações.

Contudo, os artistas independentes não têm um ponto conhecido de encontro, como uma casa editorial, e foi preciso buscar em suas páginas pessoais e perfis de Facebook dos selos independentes e dos próprios artistas, bem como sites de resenhas de material independente, o que gerou, em muitos casos, informação insuficiente. Por conta disso, grande parte da informação relativa aos artistas independentes veio da plataforma de financiamento coletivo Catarse, que apresenta inúmeros projetos de histórias em quadrinhos, o que gerou um ponto de partida para os projetos que conseguiram financiamento. E ao conferir os dados a seguir, fica claro a importância da inclusão das obras de autoria independente.

A ferramenta mais útil para este trabalho foi o site Guia dos Quadrinhos, uma plataforma colaborativa, cuja ambição é cadastrar todas as publicações de histórias em quadrinhos lançadas no Brasil. Há diversos índices de busca e uma seção do site dedicada aos lançamentos de cada mês que, além dos títulos das editoras, também apresenta os títulos de selos, coletivos, pequenas editoras e independentes. Entretanto, justamente por seu modelo colaborativo, é necessário 
que quem lê ou produz cadastre cada uma das publicações, o que, sem dúvida, faz com que o registro não seja exaustivo e ainda traz um agravante direto aos propósitos desta pesquisa: quanto mais próximo temporalmente, quanto mais recente a publicação, menos tempo ela teve de circulação, de gerar interesse e produzir engajamento do leitor de inclui-la nos bancos de dados do Guia dos Quadrinhos.

Uma forma de contornar possíveis erros oriundos de cadastro foi confirmar as informações com os autores via seus perfis oficiais na internet, resenhas e notícias de lançamento em veículos dedicados aos quadrinhos ou ao gênero de ficção científica. Mesmo ciente de que essa forma não pode garantir completamente as informações, parece ser uma tentativa de ter, pelo menos, uma dupla confirmação.

Além disso, há a certeza de que esta pesquisa não consegue garantir que todos os títulos de quadrinhos que se enquadram nos recortes explicados acima e dentro do período histórico proposto foram analisados, mas acredita-se que há uma base disponível para ser complementada, criticada, reelaborada, reestruturada, negada e melhorada. Por causa disso, além dos dados, são apresentados os títulos, o nome de seus autores e a editora ou selo do qual fazem parte. Caso alguma dessas informações não tenha sido possível de se obter, a publicação não foi incluída no banco de dados.

\section{DADOS OBTIDOS}

Os dados desta seção seguem em tabelas, para facilitar sua comparação. Alguns casos, além da soma total do ano, também há o somatório de janeiro a setembro de 2017 e 2018, para poder fornecer a comparação entre os períodos em maior igualdade de condições. Há uma progressão de informações a cada tabela, que de certa forma 
apresenta a introdução dos recortes da pesquisa, enquanto mantém a dimensão do objeto que é o foco deste artigo, a ficção científica, em relação a todos os quadrinhos e as demais publicações de insólito.

\begin{tabular}{|c|c|c|c|}
\hline \multicolumn{5}{|c|}{ TOTAL DE MATERIAIS DE HISTÓRIAS EM QUADRINHOS } \\
\hline $\mathbf{2 0 1 9}$ & $\mathbf{2 0 1 8}$ & $\mathbf{2 0 1 7}$ & \\
\hline 117 & 144 & 158 & Janeiro \\
\hline 157 & 153 & 158 & Fevereiro \\
\hline 174 & 186 & 152 & Março \\
\hline 164 & 195 & 193 & Abril \\
\hline 158 & 208 & 152 & Maio \\
\hline 168 & 179 & 188 & Junho \\
\hline 162 & 163 & 192 & Julho \\
\hline 159 & 157 & 190 & Agosto \\
\hline 154 & 179 & 178 & Setembro \\
\hline 1.413 & 1.564 & 1.561 & TOTAL EM SET. \\
\hline- & 171 & 200 & Outubro \\
\hline- & 179 & 238 & Novembro \\
\hline- & 300 & 284 & Dezembro \\
\hline 1.413 & $\mathbf{2 . 2 1 4}$ & $\mathbf{2 . 2 8 3}$ & TOTAL POR ANO \\
\hline
\end{tabular}

Tabela 1

\begin{tabular}{|c|c|c|c|}
\hline \multicolumn{5}{|c|}{ TOTAL DE MATERIAIS DE HISTÓRIAS EM QUADRINHOS } \\
NACIONAIS PUBLICADOS NO BRASIL \\
\hline $\mathbf{2 0 1 9}$ & 2018 & 2017 & \\
\hline 34 & 37 & 49 & Janeiro \\
\hline 31 & 33 & 34 & Fevereiro \\
\hline 46 & 50 & 38 & Março \\
\hline 36 & 49 & 54 & Abril \\
\hline 44 & 68 & 43 & Maio \\
\hline 43 & 57 & 56 & Junho \\
\hline
\end{tabular}




\begin{tabular}{|c|c|c|c|}
\hline 32 & 37 & 55 & Julho \\
\hline 49 & 43 & 56 & Agosto \\
\hline 27 & 53 & 54 & Setembro \\
\hline 342 & 427 & 439 & TOTAL EM SET. \\
\hline- & 47 & 45 & Outubro \\
\hline- & 58 & 93 & Novembro \\
\hline- & 162 & 139 & Dezembro \\
\hline 342 & 694 & 716 & TOTAL POR ANO \\
\hline
\end{tabular}

Tabela 2

\begin{tabular}{|c|c|c|c|c|c|c|}
\hline $\begin{array}{r}\text { TOTAL } \\
\text { PUBLICADOS } \\
\end{array}$ & $\begin{array}{l}\text { MA } \\
\text { NO B }\end{array}$ & $\begin{array}{r}\text { ERIAIS DE HI } \\
\text { ASIL COM D/ } \\
\text { EI }\end{array}$ & $\begin{array}{l}\text { TORI } \\
\text { DOS } \\
1 \text { DES }\end{array}$ & $\begin{array}{l}\text { S EM QUADF } \\
\text { A MAURICIO } \\
\text { AQUE }\end{array}$ & $\begin{array}{l}\text { NHO } \\
\text { DE SC }\end{array}$ & $\begin{array}{l}\text { JACIONAIS } \\
\text { SA PRODUÇÕES }\end{array}$ \\
\hline 2019 & & 2018 & & 2017 & & \\
\hline $\begin{array}{c}\text { Demais } \\
\text { publicações }\end{array}$ & MSP & $\begin{array}{c}\text { Demais } \\
\text { publicações }\end{array}$ & MSP & $\begin{array}{l}\text { Demais } \\
\text { publicações }\end{array}$ & MSP & \\
\hline 16 & 18 & 20 & 17 & 32 & 17 & Janeiro \\
\hline 14 & 17 & 14 & 19 & 19 & 15 & Fevereiro \\
\hline 25 & 21 & 32 & 18 & 22 & 16 & Março \\
\hline 18 & 18 & 28 & 21 & 32 & 22 & Abril \\
\hline 25 & 19 & 46 & 22 & 25 & 18 & Maio \\
\hline 22 & 21 & 38 & 19 & 39 & 17 & Junho \\
\hline 14 & 18 & 17 & 20 & 37 & 18 & Julho \\
\hline 28 & 21 & 25 & 18 & 37 & 19 & Agosto \\
\hline 13 & 14 & 34 & 19 & 33 & 21 & Setembro \\
\hline 175 & 167 & 254 & 173 & 276 & 163 & TOTAL EM SET. \\
\hline - & - & 27 & 20 & 28 & 17 & Outubro \\
\hline- & - & 39 & 19 & 72 & 21 & Novembro \\
\hline - & - & 136 & 26 & 118 & 21 & Dezembro \\
\hline 175 & 167 & 456 & 238 & 494 & 222 & $\begin{array}{c}\text { TOTAL POR } \\
\text { ANO }\end{array}$ \\
\hline
\end{tabular}

Tabela 3 


\begin{tabular}{|c|c|c|c|}
\hline \multicolumn{4}{|c|}{$\begin{array}{l}\text { TOTAL DE MATERIAIS DE HISTÓRIAS EM QUADRINHOS } \\
\text { NACIONAIS PUBLICADOS NO BRASIL QUE PODEM SER } \\
\text { ENQUADRADOS COMO INSÓLITOS }\end{array}$} \\
\hline 2019 & 2018 & 2017 & $\begin{array}{c}\text { Demais } \\
\text { publicações }\end{array}$ \\
\hline 70 & 192 & 239 & Insólito \\
\hline 60 & 204 & 185 & Infantis \\
\hline 212 & 298 & 291 & TOTAL POR ANO \\
\hline 342 & 694 & 716 &
\end{tabular}

Tabela 4

\begin{tabular}{|c|c|c|c|c|}
\hline \multicolumn{6}{|c|}{ DIVISÃO DE MATERIAIS DE HISTÓRIAS EM QUADRINHOS NACIONAIS DE } \\
TEMÁTICA INSÓLITA PUBLICADOS NO BRASIL \\
\hline $\mathbf{2 0 1 9}$ & $\mathbf{2 0 1 8}$ & $\mathbf{2 0 1 7}$ & TOTAL \\
\hline Horror & 13 & 35 & 41 & $\mathbf{8 9}$ \\
\hline Ficção Científica & 30 & 102 & 73 & $\mathbf{2 0 5}$ \\
\hline Fantasia & 17 & 66 & 71 & $\mathbf{1 5 4}$ \\
\hline TOTAL & 60 & 203 & 185 & 448 \\
\hline
\end{tabular}

Tabela 5

\begin{tabular}{|c|c|c|c|}
\hline \multicolumn{4}{|c|}{ DIVISÃO DE MATERIAIS DE HISTÓRIAS EM QUADRINHOS } \\
NACIONAIS DE FICÇÃO CIENTÍFICA PUBLICADOS NO BRASIL \\
\hline $\mathbf{2 0 1 9}$ & $\mathbf{2 0 1 8}$ & $\mathbf{2 0 1 7}$ & \\
\hline 18 & 57 & 37 & Super-herói \\
\hline 9 & 35 & 33 & Ficção Científica \\
\hline 3 & 10 & 3 & $\begin{array}{c}\text { Coletâneas com } \\
\text { elementos de FC } \\
\text { TOTAL POR ANO }\end{array}$ \\
\hline 30 & 102 & 73 & \\
\hline
\end{tabular}

Tabela 6 


\begin{tabular}{|c|c|c|c|}
\hline \multicolumn{4}{|c|}{$\begin{array}{l}\text { DIVISÃO DE MATERIAIS DE HISTÓRIAS EM QUADRINHOS } \\
\text { NACIONAIS DE FICÇÃO CIENTÍFICA PUBLICADOS NO BRASIL } \\
\text { SEM OS SUPER-HERÓIS }\end{array}$} \\
\hline 2019 & 2018 & 2017 & \\
\hline 9 & 35 & 33 & Ficção Científica \\
\hline 3 & 10 & 3 & $\begin{array}{l}\text { Coletâneas com } \\
\text { elementos de FC }\end{array}$ \\
\hline 12 & 45 & 36 & TOTAL POR ANO \\
\hline
\end{tabular}

Tabela 7

MATERIAIS DE HISTÓRIAS EM QUADRINHOS NACIONAIS DE FICÇÃO CIENTÍFICA PUBLICADOS NO BRASIL SEM OS SUPERHERÓIS POR EDITORA

\begin{tabular}{|c|c|c|c|}
\hline 2019 & 2018 & 2017 & \\
\hline 0 & 13 & 9 & $\begin{array}{c}\text { Editoras } \\
\text { comerciais }\end{array}$ \\
\hline 12 & 32 & 27 & $\begin{array}{c}\text { Pequenos selos e } \\
\text { independentes }\end{array}$ \\
\hline 12 & 45 & 36 & TOTAL POR ANO \\
\hline
\end{tabular}

Tabela 8

\section{ALGUMAS ANÁLISES DOS DADOS}

A primeira constatação necessária diante desse universo de dados é quanto à publicação de histórias em quadrinhos no Brasil se apoiar nas traduções de materiais de fora do país. Essas traduções se dão quase na totalidade por editoras, e, especificamente, por uma editora, a Panini, que é responsável pelas licenças de grande apelo popular, como Marvel e DC, entre outras. Embora o foco deste trabalho não seja essa discussão, por outro lado, ela parece incontornável. E para dar-lhe um pouco mais de materialidade, alguns dados específicos da Panini: em setembro de 2019, último mês analisado, ela foi responsável por 86 dos 154 títulos lançados no Brasil; em agosto de 2019, foram 81 do total de 159. 
Uma comparação entre a Tabela 1 e a Tabela 2, anteriormente apresentadas, mostra a enorme diferença entre a quantidade de materiais produzidos por aqui e os que são licenciados. Em todos os meses analisados, a entrada no mercado de títulos nacionais é amplamente inferior ao número de traduções (ver Figura 1). Quando a avaliação é feita por semestre (ver Figura 2), aparece uma escalada dos títulos nacionais nos últimos seis meses dos anos 2017 e 2018 (e mesmo assim, os números são somente um pouco maiores que a publicação de traduções em 3 meses de 2019). $E$ nessa grande avalanche de livros e revistas, os únicos materiais nacionais consistentemente publicados pela Panini são da Mauricio de Sousa Produções: 14 títulos entre os 81 de setembro de 2019; 21 entre os 86 de agosto de 2019. Números que nos levam a pensar que a produção nacional além da Mauricio de Sousa é ainda menor em quantidade de títulos, como está colocado na Tabela 3.

Além da MSP, ao se retirar todos os quadrinhos destinados ao público infantil tem-se a Tabela 4. Considerou-se importante buscar essa abrangência do "insólito" e aí então recortar o que seria a ficção científica. Por insólito, entende-se uma "[...] macrocategoria, abrangendo diferentes nuances entre as diversas vertentes do chamado 'fantástico'" (MATANGRANO; TAVARES, 2018, p.20).

A Tabela 5 segue a divisão proposta por Causo (2003, p.18-19) para o que ele define como literatura especulativa. Dentro dessas três categorias, o enfoque a seguir é em ficção científica. Na Tabela 6 pode ser vista uma subdivisão com os super-heróis representando mais da metade dos títulos nos três casos. Por isso, a Tabela 7 exclui essa categorização e enfoca no outro viés da produção de ficção científica no Brasil. 
Em 2017, cerca de $25 \%$ da produção de quadrinhos nacionais foi de obras que abordavam o insólito em alguma medida e a ficção científica não infantil era $5 \%$ desse todo (e outros aproximadamente $5 \%$ foram de quadrinhos de super-heróis). Leve em conta nesses dados que $40,6 \%$ das publicações foram infantis. Caso se use apenas o grupo dos quadrinhos destinados ao público não infantil, o número do insólito chega a $43 \%$ do total de publicações. Em 2018, o insólito esteve em 29,3\% das publicações gerais - aproximadamente $6,5 \%$ do total era ficção científica - e $51,5 \%$ do que foi publicado para público adulto. Com os números parciais de 2019 , o cenário é de $17,5 \%$ de obras com elementos insólitos (e 3,5\% do total é de ficção científica). Porém, há algo a ser notado.

A Tabela 1 e a Tabela 2 mostram como os meses de outubro, novembro e dezembro costumam comportar quase um terço de todos os lançamentos do ano. Boa parte dos lançamentos é de autores independentes e de pequenos selos tocados pelos próprios quadrinistas, como pode ser visto na Tabela 8. A Figura 3 mostra uma vertiginosa subida das publicações nacionais no último trimestre do ano. $O$ número de títulos em dezembro chega a ser equivalente às traduções. O motivo para isso são as importantes feiras de histórias em quadrinhos que acontecem no Brasil nesse período.

A ComicCon Experience (CCXP), em São Paulo, tem um espaço para os artistas de quadrinhos venderem diretamente suas obras ao público e tem sido uma espécie de norte para os lançamentos de histórias em quadrinhos do ano. Além da CCXP, há também em São Paulo a Feira Miolos e Des.Gráfica, entre outras pelo país. 


\section{CONCLUSÃO}

A cena independente é muito importante para os autores nacionais como um todo, mas parece ser de especial relevo para produtores de fantástico brasileiro em quadrinhos. A relação da história em quadrinho com o pulp e com o underground são marcas determinantes ainda hoje de boa parte da produção nacional.

As ferramentas de financiamento coletivo, sobretudo o Catarse, têm contribuído para que autores consigam bancar a impressão de suas obras; há também o caso das edições de baixo custo editorial, o que permite que o autor financie a obra futura com a venda da atual, em uma relação direta com seus leitores.

Considerando-se que as revistas pulp tinham um valor baixo para compra e produção, assim como também a publicação de zines underground, em que o trabalhador do meio de produção, o vendedor e o artista se conjugavam na mesma pessoa. Se não há editora disposta a bancar seu material, um autor pode embarcar no "faça-você-mesmo". Essas características são tão importantes, que não é possível pensar na produção nacional de histórias em quadrinhos sem levá-las em conta. E o mesmo parece valer para a produção de ficção científica.

No período analisado não há variações consideráveis de publicação e pode-se dizer, por esse recorte, que se tem publicado pouca ficção científica brasileira em quadrinhos. Chama a atenção a baixa presença das editoras na produção nacional de insólito como um todo, sobretudo na ficção científica. Mas parece que essa constatação fala mais do cenário de quadrinhos no Brasil de modo geral do que da ficção especulativa. 
Do todo publicado no Brasil, aproximadamente um terço é de material nacional. E entre os materiais nacionais, ainda há uma parcela muito significativa da Mauricio de Sousa Produções. Ou seja, o quadrinho disponível no mercado brasileiro ainda é muito ligado a uma indústria. Dentre todas as publicações que sobram que não são traduções nem MSP, há os mais diversos interesses dos autores, como a autobiografia, a reportagem, o ensaio, o humor e, claro, o insólito, o que explicaria, em partes, o porquê de números tão tímidos de FC diante do total de publicações.

Faz-se pouco quadrinho no Brasil se comparado ao que é publicado e boa parte desse volume se deve aos independentes, que embora não estejam imunes aos modismos e influências da indústria cultural, não estão atrelados a ela como um trabalhador contratado está. Nesse campo um pouco mais livre, os autores independentes podem se dedicar a aquilo que a indústria deixa de lado. E o insólito não poderia estar mais bem acomodado do que num espaço longe dos holofotes das grandes campanhas de marketing e de lançamento das grandes editoras, mas ainda próximo aos leitores. 


\section{FIGURAS}

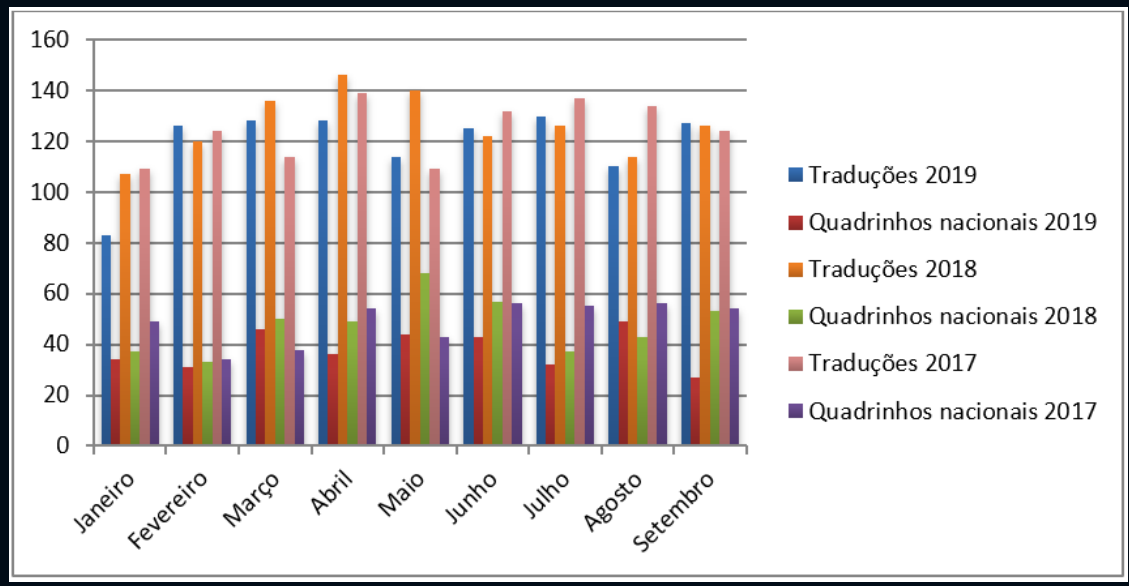

Figura 1 - Gráfico comparativo entre as publicações nacionais e traduzidas de história em quadrinhos de janeiro a setembro dos 3 anos analisados.

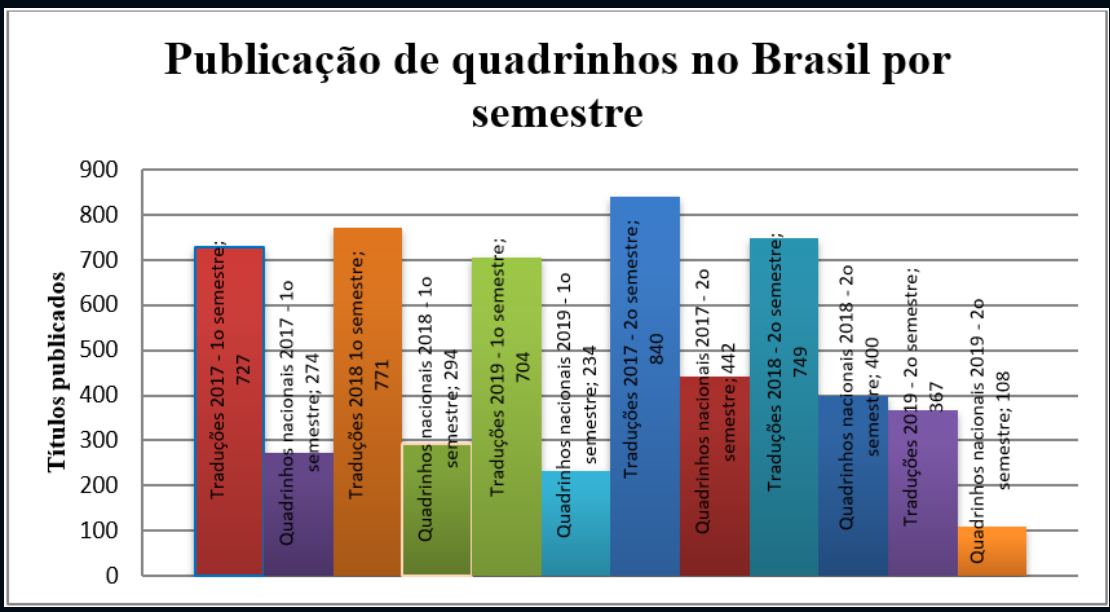

Figura 2 - Gráfico comparativo entre as publicações nacionais e traduzidas de história em quadrinhos em cada semestre dos 3 anos analisados. 


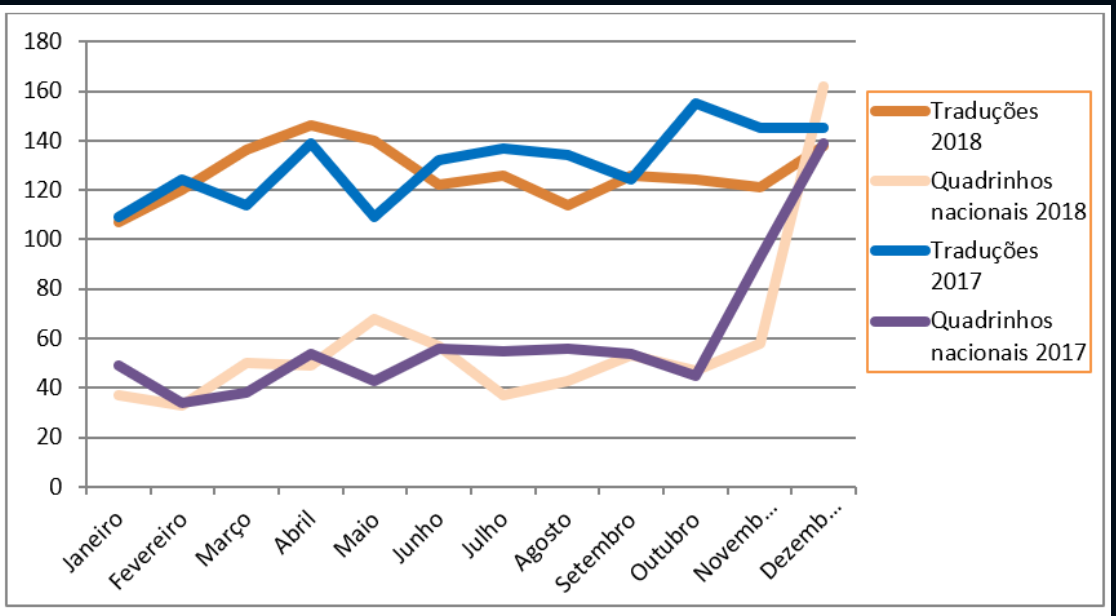

Figura 3 - Gráfico comparativo entre as publicações nacionais e traduzidas de história em quadrinhos de 2017 e 2018.

\section{REFERÊNCIAS}

CATARSE (c2019). Catarse In http://www.catarse.me. Acesso em 29.Out.2019.

CAUSO, Roberto de Sousa (2003). Ficção Científica, Fantasia e Horror no Brasil: 1875 a 1950, Belo Horizonte: Ed. UFMG.

GUIA DOS QUADRINHOS (c2019). Guia dos Quadrinhos In http://www. guiadosquadrinhos.com Acesso em 29.Out.2019.

JUNIOR, Gonçalo (2004). A Guerra dos Gibis: A formação do mercado editorial brasileiro e a censura aos quadrinhos 1933-1964. São Paulo: Companhia das Letras.

MATANGRANO, Bruno Anselmi; TAVARES, Enéias (2018). Fantástico Brasileiro: O insólito Literário do Romantismo ao Fantasismo. Curitiba: Arte \& Letra.

\section{ANEXO}

Lista das obras de ficção científica nacionais computadas, sem incluir as de super-herói.

2017

Anexia (Ugra Press), de Gabriel Goes e Pedro D’Apremont - distopia e humor 
As Crônicas de Os poucos e os Amaldiçoados (independente), de Felipe Cagno e outros - western distópico

Bipolar (independente), de Renan Rivero, Samuel Bono, Diogo Torres e Omar Viñole - FC futurista

Calango 2 (independente), de Cristiano Seixas e Eduardo Pansica - sertão apocalíptico

Cavalo de Teta 1 (independente), Diego Gerlach, João Pinheiro, Schiavon, Evandro Alves e MZK - coletânea com elementos distópicos em algumas histórias

Classified 1 independente), de Felipe Cagno e Marcelo Costa - História alternativa e ação

Cyberpunk 1 (independente), autor desconhecido - FC Cyberpunk

Desastres Ambulantes (Jupati), de Guilherme Smee e Romi Carlos - FC e Guerra Divisão 51 (Draco), de Rafa Santos e Wagner Elias - Realidades alteradas e humor

Don Brothers: Suor Stress e Cafeína (independente), de Kaji Pato, Max Andrade, Rafa santos, Wagner Elias - coletânea com elementos FC

Doppler (independente), de Doug Lira, Rafa Louzada e Rainor Marinho - FC futurista

Eventos Semiapocalípticos: Eduardo e Afonso (independente), de Yoshi Tice - FC e aventura

Green Slimes (independente), de Victor Reis - FC espacial

Guerra dos Golfinhos (Atomik), de Flavio Calazans - futuro distópico/utópico (republicação)

Hacking Wave (independente), de Larissa Pamieri, Zaheer e Pedro Okuyama Cyberpunk

Homo Eternus (Criativo), de Gazy Andraus - FC filosófica

Hooligan 1 (independente), de Jayson Santos - FC pós-apocalíptica

Hooligan 2 (independente), de Jayson Santos - FC pós-apocalíptica

Já Era (Lote 42), de Felipe Parucci - FC Espacial

Lorenna: Vingança Radioativa (independente), de Marcio Abreu e Julio Santos - FC pós-apocalíptica 
Nóia (Escória Comix), de Diego Gerlach - humor, distopia leve O Planta (independente), de Gustavo Ravaglio - FC retrofuturista

Onda de Crime (Escória Comix), de Vitor Valença - distopia underground; Oráculos (Criativo), de Edgar Franco - FC filosófica

Pile Up (independente), de Bruno Soares - FC Espacial Ponchiki (independente), de Dora Coelho - FC espacial R'Lyeh Boy (independente), de Caio Oliveira - FC paródia Ramthar (Mythos), de Mike Deodato Jr. e Mozart Couto - super-herói e distopia RGB Dead Pixel (independente), de Davi Augusto - Cyberpunk samurai Salto (AVEC), de Rapha Pinheiro - aventura steampunk Space Opera (Draco), vários autores - coletânea de space opera inéditas Úlcera Vortex 1 (Escória Comix), de Victor Bello - FC e fantasia underground Úlcera Vortex 2 (Escória Comix), de Victor Bello - FC e fantasia underground Wilson Lanchão 1 (Escória Comix), de Lobo ramirez - FC e ação underground Wilson Lanchão 2 (Escória Comix), de Lobo ramirez - FC e ação underground Zhor o Atlanta (Criativo), de Walmir Amaral e outros - super-herói republicação 2018

10 Dias Perdidos (Independente), de Sam Hart - Viagem no tempo

3 Anos de Glória (Caligari), de Denis Mello - Distopia futurista

A Todo Vapor (independente), de Enéias Tavares e Fred Rubim - Steampunk Acelera SP (independente), de Cadu Simões, Juliano Kaapora e Sam Hart Futurismo indígena

Adagio (AVEC), de Felipe Cagno, Sara Prado, Brão, Natália Marques, Deyvison Manes - Cyberpunk

Agente Sommos (independente), de Flavio Luiz - FC espionagem e humor As Novas Amazonas (independente), de Leonardo Santana - Distopia e aventura Asteroides (escória Comix/ Ugra Press), de Lobo Ramirez - FC futurista Batalha dos Três Mundos (Jambô), de Alexandre Lancaster e Israel de Oliveira FC Espacial 
Cangaço Overdrive (Draco), de Zé Wellington e outros - FC futurista no sertão Cavalo de Teta 2 (independente), Diego Gerlach, João Pinheiro, Schiavon, Evandro Alves e MZK - coletânea com elementos distópicos em algumas histórias

Corruption (independente), de Tom Gomes e outros - Cyberpunk

Desafiadores do Destino (AVEC), de Felipe Castilho, Mauro Fodra, Mariane Gusmão - aventura steampunk

Destination 1 (independente), de Alessio Esteves e Lobo Loss - Western cyberpunk

Do Outro Lado (independente), de Claudio Alves e Dhaius Oliveira - Distopia Entrespaço (independente), de Daniel Sousa - FC espacial Enxaqueca (independente), de Felipe Parucci - FC e humor Eventos Semiapocalípticos: Gilmar (independente), de Yoshi Tice - FC e aventura Febre (independente), de Gabriel Kolbe, Matias Streb e Jader Corrêa - FC espacial e steampunk

Graphic MSP - Astronauta: Entropia (Panini), de Danilo Beyruth - FC Espacial Gynoide (independente), de Larissa Pamieri e Hugo Nanni - FC futurista HVírusQ (Criativo), de vários autores - contém histórias com temas de FC Imaginário em Quadrinhos volume 5 (Draco), organização de Raphael Fernandes - coletânea com algumas histórias de temática FC Justiça Sideral: recomeços (AVEC), de Deyvison manes, Netho Diaz - space opera Know Haole 8 (independente), de Diego Gerlach - sutil distopia Le Chevalier 2 (AVEC), de A.Z. Cordenonsi e Fred Rubim - FC aventura Máquinas Não Choram (independente), de André Turtelli Poles e Renato Quirino - FC futurista

Música Para Antropomorfos (Zarabatana), de Fabio Zimbres - Distopia underground republicação

Os Poucos e os Amaldiçoados 3 (independente), de Felipe Cagno e Fabiano Neves - Western distópico

Os Poucos e os Amaldiçoados 4 (independente), de Felipe Cagno e Fabiano Neves - Western distópico 
Pé-de-Cabra 1 (independente), organização de Carlos Panhoca - coletânea com algumas histórias de temática FC

Periferia Cyberpunk (Draco), organização de Raphael Fernandes - Cyberpunk Quackranger (independente), de Alexandre dal Gallo - FC espacial e combate Quad 4 (independente), de Aluísio Santos, Diego Sanches, Eduardo Ferigato e Eduardo Schaal - Futuro pós-apocalíptico

Quadritos 14 (independente), organização de Marcos Freitas - coletânea com algumas histórias de temática FC

Realidade (Pé-de-Cabra), de Cris Onofre - FC Futurista

Reino do Vazio 1 (independente), de Claudio Alves, Daniel Alves e Thiago Ribeiro - Distopia

Revista Refluxo1 (independente), de Bruno Soares, Fralvez, Samuel Sajo, Sergio R.M> Duarte, Thiago Felix - FC

Silas (AVEC), de Rapha Pinheiro - aventura steampunk

Teocrasília (Caligari), de Denis Mello - Distopia futurista

Teocrasília Extra 1(Caligari), de Denis Mello - Distopia futurista

Teocrasília Extra 2 (Caligari), de Denis Mello - Distopia futurista

Última Cova (independente), de Armando Fonseca e Gustavo Hildebrand Distopia

Vagabundos do Espaço volume 1 (Draco), de Raphael Salimena - space opera e humor

Zica 5 (independente), de vários autores - coletânea com algumas histórias de temática FC

\section{9}

10 Dias Perdidos 2 (Independente), de Sam Hart - Viagem no tempo

Corpos-Secos (independente), de Rogério Faria e Raimundo Guimarães Distopia.

Enjoy the Silent (independente), de João Eddie - - coletânea com algumas histórias de temática FC

Eventos Semiapocalipticos: Gabriela (independente), de Yoshi Tice - FC e aventura 
Frankenstein 200 (Clepsidra), de Alex Mir, Ana Fiori, Hector Lima, Jorge de Barros, Lexy Soares, Lillo Parra, Alex Genaro, Décio Ramirez, Gio Guimarães, Pri Wi, Psicotikkaa e Ton Albuquerque - coletânea com algumas histórias de temática FC

Noite Escura (independente), de Andy Corsant - FC futurista

Os Poucos e os Amaldiçoados 5 (independente), de Felipe Cagno e Fabiano Neves - Western distópico

Pé-de-Cabra 2 (independente), organização de Carlos Panhoca - coletânea com algumas histórias de temática FC

Petgod (independente), de Hiago NC - FC futurista

Quadritos 15 (independente), organização de Marcos Freitas - coletânea com algumas histórias de temática FC

STRGRL 1 (independente), de Lucas Mendonça - FC Espacial

Wilson Lanchão 3 (Escória Comix), de Lobo Ramirez - FC e ação underground 